\title{
“ELA É BOA DE CUSPIR, MALDITA GENI!": REFLEXÕES SOBRE VIOLÊNCIAS CONTRA OS CORPOS DISSIDENTES DE TRAVESTIS EM CAMPO GRANDE/MS
}

\author{
"SHE'S GOOD TO SPIT ON, CURSED GENI!": REFLECTIONS ON VIOLENCE AGAINST DISSIDENT BODIES OF \\ TRANSVESTITES IN CAMPO GRANDE/MS
}

\section{RESUMO}

Este trabalho reflete, a partir de inúmeras condições de subalternização, as múltiplas violências dirigidas aos corpos dissidentes de travestis na cidade de Campo Grande, capital do Estado de Mato Grosso do Sul/MS. As reflexões do estudo partem de referenciais teórico-metodológicos decorrentes de uma perspectiva pós-colonial e de um feminismo pós-estruturalista, que consideram que as violências engendradas contra as travestis decorrem principalmente do fato de elas performatizarem uma identidade de gênero distinta em relação àquilo que determinada os seus sexos biológicos. Em suma, a pesquisa valeu-se da coleta de dados a partir de dois procedimentos: (I) investigação documental relacionada aos casos de mortes de travestis e transexuais no Brasil e; (II) cinco entrevistas com travestis em contextos de prostituição, na cidade de Campo Grande/MS. A análise dos dados revelou o conjunto de violências diretas (agressões, espancamentos e mortes) e de violências indiretas (discriminações, além de negligências quanto à direitos básicos) contra as pessoas travestis no território em investigação.

Palavras-chave: Violência. Travestis. Feminismo Pós-Estruturalista.

\begin{abstract}
This work reflects, from countless conditions of subordination, the multiple violence against dissident bodies of transvestites in the city of Campo Grande, capital of the State of Mato Grosso do Sul/MS, in the Brazilian Midwest. The reflections of this study start from the theoretical-methodological references resulting from a postcolonial perspective and a poststructuralist feminism, which consider that violence against transvestites derives mainly from the fact that they performatize a gender identity distinct from their biological sexes. In order to reflect on these concerns, the present study was based on the collection of data from two procedures: (I) documental research related to cases of transvestite and transsexual deaths in Brazil; (II) five interviews with transvestites in contexts of prostitution, in the city of Campo Grande/MS. Data analysis reveals the set of direct violence (aggressions, beatings and deaths) and indirect violence (discrimination and negligence regarding basic rights) against transvestites in the territory under investigation.
\end{abstract}

Gabriel L. P. Nolasco

Universidade Católica Dom Bosco (UCDB). Email: nolasco.msn@hotmail.com

Zaira de A. Lopes

Universidade Federal de Mato Grosso do Sul (UFMS). Email: zairaal@gmail.com

Dyego de O. Arruda

Centro Federal de Educação Tecnológica Celso Suckow da Fonseca (CEFET/RJ).Email:dyego.arruda@gmail.com 
Keywords: Violence. Transvestites. Poststructural Feminism.

\section{Aspectos preliminares}

Joga pedra na Geni!

Ela é feita pra apanhar!

Ela é boa de cuspir!

Ela dá pra qualquer um!

Maldita Geni!

(“Geni e o Zepelim”, Chico Buarque, 1978)

Geni, vista como um ser abjeto e subalternizado, passível de toda a sorte dos piores estigmas e violências, é a personagem central de uma música composta por Chico Buarque, em 1978 (Araujo, 2018; Butler, 2016). Ao longo da canção, percebe-se que mesmo no contexto em que Geni consegue "salvar" o território em que vivia de um ataque de um poderoso comandante e seu temido Zepelim, ainda assim as pessoas continuam tratando Geni como um ser detentor de um corpo que merece ser permanentemente apedrejado, cuspido, usado, desumanizado e, portanto, violentado (Zago, 2014).

Neste artigo, partimos da premissa de que as pessoas travestis são seres tais como a Geni de Chico Buarque: possuem corpos tidos/lidos como ininteligíveis e que, ao desafiarem a perspectiva do gênero pautado no essencialismo biológico, despertam a ira e o ódio de uma sociedade que, historicamente, construiu suas relações socioafetivas calcadas na heteronormatividade enquanto valor universal e natural (Jesus, 2014; Dias \& Souza, 2019; Pelúcio \& Duque, 2013).

No Brasil, o contexto de ódio, repulsa e violência às travestis é especialmente relevante. Segundo os últimos dados sistematizados pela Associação Nacional de Travestis e Transexuais (ANTRA, 2019), o país foi aquele em que mais morreram, no mundo, pessoas travestis e transexuais, sobretudo em função da ocorrência de práticas de transfobia e transfeminicídio. Só no ano de 2018 foram 163 mortes registradas, mais do que o dobro do México, o segundo país que mais mata travestis e transexuais.

Chama especial atenção o fato de que, no contexto brasileiro, as situações de violência contra travestis e transexuais são especialmente cruéis. As mortes dessas pessoas, em sua grande maioria, são espetacularizadas e ritualizadas; os corpos são mutilados, não raro destrinchados e esquartejados, numa dinâmica em que se expõe, tal como um troféu, o horror e a negação sociais àqueles corpos e seres considerados abjetos e "matáveis" (Bento, 2014 e 2018; ANTRA, 2019). O caso de Dandara dos Santos, uma travesti, negra e periférica, morta em 2017 no Estado do Ceará em plena luz do dia, é uma ilustração dos supracitados aspectos: Dandara foi torturada (com direito a gritos, ofensas, chineladas, socos, chutes, pedradas e pauladas), e finalmente morta 
a tiros por um grupo de agressores, que filmaram e divulgaram, na internet, todo o rito de execução sumária da vítima (Melo, 2018).

De todo modo, a morte e violência física são apenas a "ponta do iceberg" quando se considera a realidade vivida pelas travestis. Há um conjunto de outras violências relegadas a elas, na medida em que não se respeita o direito ao uso do nome social e à identidade de gênero; não se considera as práticas de transfobia e transfeminicídio enquanto crimes tipificados na legislação penal; não se institucionaliza uma agenda de políticas públicas voltada especificamente para a população de pessoas travestis e transexuais; sem contar a evidente invisibilidade das pessoas travestis e transexuais na mídia, nas estatísticas oficias, no mercado de trabalho e no contexto acadêmico. Em suma, o local destinado aos corpos (não) inteligíveis de travestis é, sumariamente, a prostituição e a subalternidade (Giongo, Menegotto \& Petters, 2012).

Portanto, ante às supracitadas contextualizações, este trabalho cumpre o dever de refletir o contexto de múltiplas violências relegadas às travestis na cidade de Campo Grande, capital do Estado de Mato Grosso do Sul, no Centro-Oeste brasileiro.

É importante o esforço sistemático de reflexão em torno do objetivo de pesquisa acima delineado. Julgamos que, na medida em que se (re)conhece toda a dinâmica da violência contra as travestis, é possível que sejam empreendidas estratégias, sobretudo do ponto de vista das políticas públicas, para se coibir, de alguma forma, essas violências, fazendo com que as Dandaras e Genis não sejam mais cuspidas, chutadas, violentadas, apedrejadas e/ou mortas rotineiramente.

Para que o esforço reflexivo do artigo fosse possível, foram utilizadas duas fontes de dados: (a) investigação documental do dossiê da ANTRA, publicado em 2019, que traz as estatísticas nacionais de assassinatos e violências contra travestis e transexuais e; (b) contatos, diálogos e entrevistas com cinco travestis na cidade de Campo Grande/MS, que nos permitiram acessar determinados territórios pelos quais elas circulam, além de conhecer e até presenciar casos de violências contra elas.

\section{Luz, câmera e ação: lá vem a transgressora!}

Consideramos que as pessoas que performatizam uma identidade de gênero distinta em relação aos seus sexos biológicos - tal como as travestis do nosso estudo -, são verdadeiras transgressoras: elas rompem com as determinações correspondentes às genitálias com as quais nasceram, dando luz à uma identidade de gênero que não coaduna com a natureza biológica e determinista que prevê um alinhamento (e, portanto, uma inteligibilidade) entre os marcadores sexo, gênero, práticas sexuais e desejo (Nolasco, 2018).

Nesse ínterim, entende-se que o gênero é uma construção social, que independe do determinismo do sexo biológico (Butler, 2004). Em outros termos, não é porque uma pessoa possui pênis que ela necessariamente será homem; ao passo que não é a presença da vagina que faz com que alguém seja mulher: a manifestação 
do "ser homem", "ser mulher" ou "não ser nem homem e nem mulher" dependerá do modo como a pessoa identifica-se, manifesta os seus desejos e, eventualmente, empreende um conjunto de tecnologias (tais como o uso de próteses, silicones, hormônios, roupas específicas, gestuais e afins) para modificar seus corpos e, desse modo, performatizar um determinado gênero; ou mesmo não performatizar gênero algum (Carvalho, 2018; Bagagli, 2016; Miskolci \& Pelúcio, 2007).

É interessante pensarmos, nesse momento, no conceito de performatividade, de Butler (2016). No entender da autora, a teoria da performatividade está relacionada com um conjunto de práticas que, na medida em que são empreendidas e reiteradas pelos corpos sexuados, vão construindo, não raro de modo natural e espontâneo; outras vezes de modo deliberado e intencional, a identificação com um determinado gênero (D’Angelo et al, 2018). Sendo assim, Borba (2014) lembrará que as cores, roupas, manifestações dos desejos, o modo como se fala, além dos detalhes do corpo e das posições corporais - só para citarmos alguns poucos exemplos - vão permitindo, aos sujeitos sexuados, a identificação com um determinado gênero, independentemente da genitália e, portanto, do sexo biológico das pessoas.

Duque (2017, p. 499), em suas pesquisas e estudos envolvendo as travestis, apresenta o conceito de passabilidade, que está intimamente relacionado com “(...) processos de reconhecimento, ou de busca de reconhecimento, que se dão pela reiteração de normas e convenções de inteligibilidade de gênero no sentido mais hegemônico desse processo". Toda a dinâmica performática das travestis e, consequentemente, o modo como elas apresentam-se em contextos sociais de interação, poderão permitir (ou não) uma maior e melhor passabilidade, facilitando (ou não) o reconhecimento social da travesti enquanto mulher (Duque, 2012).

Julgamos que toda essa dinâmica da passabilidade das travestis é algo que engendra ódio, rancor e violência por parte da sociedade. Ódio por condutas, comportamentos e corpos desviantes que "bagunçam" os marcadores sexo e gênero; rancor porque o "ser feminino" da travesti desafia a perspectiva heteronormativa e patriarcal dominantes nas sociedades contemporâneas; violência porque partese da perspectiva de que as travestis, por performarem seres considerados abjetos e ininteligíveis, podem ser submetidas à processos deliberados de anulação, apagamento e morte.

Bento (2014, p. 1) lembra que as travestis sofrem de um duplo processo de violência: primeiro por associarem-se ao feminino, que já é algo socialmente desvalorizado; e depois por terem nascido com pênis, o que implica em “(...) um transbordamento da consciência coletiva que é estruturada na crença de que a identidade de gênero é uma expressão do desejo dos cromossomas e dos hormônios".

Sabe-se que as múltiplas violências sofridas pelas travestis vão das mais diretas e agudas até as mais sutis e, aparentemente, “inocentes” (Lopes, 2009). As violências mais diretas associam-se principalmente aos episódios de assassinatos, linchamentos e agressões físicas mais contundentes, ao passo que as violências sutis não raro estão ligadas à estratagemas que, de modo direto ou indireto, negam direitos básicos e cidadania às travestis. No entender de Minayo e Souza (1997) as várias 
fontes de violência contra grupos específicos - tais como o das travestis - devem ser tratadas como problemas de saúde pública, sendo, portanto, questões fundamentais para a transformação de valores e condutas sociais.

Ademais, deve-se ainda adicionar que muitas travestis são acometidas por um acirramento da violência em função de "concentrarem", em suas trajetórias de vida, outros marcadores sociais da subalternidade, tais como os marcadores raça e classe social (Lima, 2018; Efrem Filho, 2016). Muitas travestis são negras, pobres e periféricas; ao passo que são relegadas aos territórios subalternizados e perigosos (tais como os territórios da prostituição de rua), numa dinâmica que as fazem reféns de ainda mais violência, para além daquela que já as acomete em função da manifestação de suas identidades de gênero (Ferreira, 2014; Costa et al, 2015).

Porém, quais os números e detalhes da violência contra as travestis, no Brasil? O tópico que segue começa a explorar essa questão, desnudando as informações relativas sobretudo às formas de violência direta e explícita contra as travestis.

\section{As pedras na Geni}

As travestis no Brasil, tal como a Geni de Chico Buarque, são constantemente "apedrejadas", na maioria das vezes de modo cruel e fatal. O quadro 1 ilustra tal perspectiva, a partir do dossiê dos assassinatos e violências contra travestis e transexuais, no ano de 2018, produzido pela Associação Nacional de Travestis e Transexuais (ANTRA).

Quadro 1: Detalhes dos assassinatos de travestis e transexuais no Brasil, em 2018

\begin{tabular}{|c|c|}
\hline Unidade de análise & Dados \\
\hline Total de mortes & $\begin{array}{l}163 \text { (sendo } 158 \text { travestis e mulheres transexuais, } 4 \\
\text { homens transexuais e } 1 \text { pessoa não-binária }\end{array}$ \\
\hline $\begin{array}{c}\text { Estados da Federação com mais } \\
\text { mortes }\end{array}$ & $\begin{array}{c}\text { Rio de Janeiro (16 casos), Bahia (15), São Paulo (14) e } \\
\text { Ceará (13) }\end{array}$ \\
\hline $\begin{array}{l}\text { Regiões da Federação com mais } \\
\text { mortes }\end{array}$ & Nordeste (59 casos), Sudeste (45) e Sul (20) \\
\hline Idade das vítimas & $\begin{array}{c}\text { Entre } 17 \text { e } 29 \text { anos (6o, } 5 \% \text { do total); } 30 \text { e } 39 \text { anos }(29,1 \%) \\
\text { e } 40 \text { e } 49 \text { anos }(10,5 \%)\end{array}$ \\
\hline Ocupação das vítimas & Profissionais do sexo (65\% dos casos) \\
\hline Raça das vítimas & Maioria pretas e pardas ( $82 \%$ dos casos) \\
\hline $\begin{array}{c}\text { Principais métodos e } \\
\text { instrumentos usados no } \\
\text { assassinato }\end{array}$ & $\begin{array}{c}\text { Arma de fogo ( } 53 \% \text { dos casos), arma branca ( } 21 \%) \text { e } \\
\text { espancamento ( } 19 \%)\end{array}$ \\
\hline Local do assassinato & Maioria na rua ou locais públicos (6o\% dos casos) \\
\hline
\end{tabular}

Fonte: Elaborado pelos autores a partir do dossiê da ANTRA (2019). 
De uma maneira geral, é possível inferirmos, com base nos dados acima sistematizados, que as travestis que são mortas no Brasil possuem um perfil relativamente homogêneo: são muito jovens, negras, atuam como profissionais do sexo e são assassinadas em locais públicos, não raro com requintes de crueldade.

Não obstante, some-se ainda o fato de que as travestis vítimas de agressões e assassinatos, em sua grande maioria, são expulsas muito precocemente de casa e do contexto familiar (em média, aos 13 anos de idade), ao passo que também abandonam muito cedo a escola. Estes aspectos acabam empurrando as travestis de modo compulsório para a prostituição de rua, para a marginalização e para a violência (TGEU, 2017).

É importante reiterar que, conforme já comentado neste artigo, as mortes das travestis, em sua esmagadora maioria, são cruéis. Muito embora o quadro 1 sinalize que mais da metade das mortes são causadas por disparos de arma de fogo, ainda assim vale a pena esclarecer que a maioria não são mortes "objetivas", ou seja: os assassinatos obedecem à um rito permeado por muita violência e uso excessivo da força, de tal modo que o disparo de arma de fogo apenas "finaliza o serviço" (ANTRA, 2019). Acrescente-se ainda a constatação de que, em muitas circunstâncias, são feitos muitos disparos nas vítimas, em especial, nas genitálias e nos rostos.

Chama ainda a atenção o fato de que grande parte dos assassinatos é perpetrado na rua ou em locais públicos. Nesse ínterim, Bento $(2014$, p. 2) esclarece que a "morte espetacularizada" das travestis possui uma dupla função: demonstrar poder e força, o que é muito comum quando os algozes são homens e; reforçar o caráter subalternizado e abjeto das travestis, contribuindo com “(...) coesão e reprodução da lei de gênero que define que somos o que nossas genitálias determinam”.

\section{Os pedriscos...}

Consideramos que, para além da violência física direta, que implica em morte, as "Genis" deste trabalho também são reiteradamente acometidas por violências mais sutis e indiretas. Numa perspectiva metafórica, consideramos que tais formas de violência são como "pedriscos": de menor proporção em relação às "pedras jogadas na Geni”, aparentemente inocentes, mas que também causam enorme dor e sofrimento.

Tendo como propósito lançar luz no contexto de violências indiretas sofridas pelas travestis, valemo-nos de uma pesquisa de campo em que o nosso olhar foi direcionado para a compreensão do modo como cinco travestis (Agrado, Zahara, Vera Cruz, Lola e Paquita' ${ }^{1}$ ) percebiam a realidade e, por conseguinte, o contexto de múltiplas violências que cotidianamente sofriam.

1 Os reais nomes das pessoas travestis pesquisadas foram preservados. Agrado, Zahara, Vera Cruz, Lola e Paquita são, portanto, nomes fictícios, inspirados em personagens de filmes do cineasta espanhol Pedro Almodóvar que, em sua obra, tangenciou aspectos relativos às discussões de gênero (Rodrigues \& Heilborn, 2014). 
Em suma, os nossos primeiros contatos com as travestis se deram nos idos de 2016, no âmbito do Instituto Brasileiro de Inovações pró-Sociedade Saudável Centro Oeste (IBISS|CO), uma Organização da Sociedade Civil (OSC) presente na cidade de Campo Grande, capital do Estado de Mato Grosso do Sul. As nossas pesquisadas foram "descobertas" pelo IBISS|CO em função de ações do projeto denominado de "Viva Melhor Sabendo - VMS", que tinha como base um acordo de cooperação mútua entre OSC's e o Ministério da Saúde, com ações estratégicas para a testagem rápida, via fluído oral, para o HIV em populações-chave (Oliveira \& Nolasco, 2017).

Agrado, Zahara, Vera Cruz, Lola e Paquita participaram da testagem de fluído oral para o vírus HIV, sendo que, de todas elas, apenas Vera Cruz já tinha ciência de sua sorologia. Muito embora Vera Cruz soubesse de sua condição sorológica reagente para o vírus HIV, ainda assim ela não fazia qualquer tipo de tratamento, o que a colocava ainda mais em situação de vulnerabilidade. Descobrimos ainda, na medida em que fomos interagindo com esta participante, que ela também já havia tido contato com a sífilis.

Ao ampliarmos as nossas interações com as supracitadas travestis, fomos, paulatinamente, "adentrando" o universo em que essas pessoas sobrevivem e constroem seus modos de subjetivação. Na medida em que nos sentimos seguros, providenciamos um convite para que elas participassem de uma investigação de caráter acadêmico ${ }^{2}$, na qual seriam submetidas a entrevistas em profundidade. Diante do aceite das travestis, entregamos a elas um Termo de Consentimento Livro e Esclarecido (TCLE), que continha todos os detalhes e dinâmicas da pesquisa.

As entrevistas, devidamente autorizadas pelas participantes da pesquisa, ocorreram nos meses de novembro e dezembro de 2017. Os diálogos foram gravados e, posteriormente, transcritos. É importante esclarecer que, de posse das entrevistas transcritas, procuramos triangular as falas das nossas entrevistadas com as informações decorrentes da observação participante, a fim de que pudéssemos ter um quadro geral que revelasse as múltiplas violências sofridas e os modos de subjetivação das nossas entrevistadas. Não obstante, destaque-se ainda que assumimos, na análise dos dados empíricos, o diálogo com pressupostos pós-coloniais e de um feminismo pós-estruturalista, para a compreensão das realidades que nos foram apresentadas.

Em suma, as travestis que participaram da investigação são jovens (média de idade de pouco mais de 22 anos), possuem baixo nível de escolarização, são solteiras, não moram com familiares (à exceção de Agrado e Paquita), além de serem, todas, profissionais do sexo há pelo menos dois anos. O quadro 2 traz maiores detalhes acerca das travestis pesquisadas.

2 Tal pesquisa foi submetida ao comitê de ética em pesquisa com seres humanos, da Universidade Federal de Mato Grosso do Sul (UFMS). A dinâmica da pesquisa foi aprovada pelo referido comitê em 26/04/2017 - processo no 65843117.2.000o.oo21. 
Quadro 2: Caracterização das participantes da pesquisa

\begin{tabular}{|c|c|c|c|c|c|c|}
\hline Nome & Idade & Naturalidade & Escolaridade & $\begin{array}{c}\text { Estado } \\
\text { Civil }\end{array}$ & $\begin{array}{l}\text { Tempo de } \\
\text { "batalha" }\end{array}$ & Reside com \\
\hline Agrado & 22 anos & $\begin{array}{l}\text { Campo Grande } \\
\text { (MS) }\end{array}$ & $\begin{array}{c}1^{\mathbf{o}} \text { ano do } \\
\text { ensino médio }\end{array}$ & Solteira & 2 anos & Família \\
\hline Zahara & 24 anos & Corumbá (MS) & $\begin{array}{c}\text { 8a série } \\
\text { do ensino } \\
\text { fundamental }\end{array}$ & Solteira & 7 anos & Pensionato \\
\hline Vera Cruz & 20 anos & São Luís (MA) & $\begin{array}{l}1^{\circ} \text { ano do } \\
\text { ensino médio }\end{array}$ & Solteira & 3 anos & $\begin{array}{l}\text { Pensionato/ } \\
\text { Casa de } \\
\text { acolhimento }\end{array}$ \\
\hline Lola & 22 anos & Curitiba (PR) & Não informado & Solteira & 7 anos & Pensionato \\
\hline Paquita & 23anos & Ladário (MS) & $\begin{array}{c}5^{\mathrm{a}} \text { série } \\
\text { do ensino } \\
\text { fundamental }\end{array}$ & Solteira & 9 anos & $\begin{array}{l}\text { Amigos e } \\
\text { família }\end{array}$ \\
\hline
\end{tabular}

Fonte: Dados da pesquisa.

Logo nos primeiros contatos com as nossas entrevistadas, descobrimos, de modo direto e incisivo, os jogos de poder, além da aparente violência, nos espaços em que as travestis circulam e empreendem as suas atividades enquanto profissionais do sexo. Certa feita, ao circularmos por áreas em que as travestis normalmente "batem ponto" na cidade de Campo Grande/MS, fomos abordados por um homem que, posteriormente, soubemos que era o cafetão e traficante naquele território. Fomos perguntados, de modo incisivo, o que estávamos fazendo ali e o motivo pelo qual falávamos tanto com as travestis. Após explicarmos quem éramos, qual o nosso propósito, além de mostrarmos os nossos uniformes e identificação do IBISS|CO, fomos autorizados a permanecer naqueles espaços, principalmente porque esse homem - reconhecido como o "dono" do território - entendeu que o nosso propósito ali era prestar serviços de prevenção em saúde, às travestis.

Foi emblemático o expediente em que fomos abordados pelo cafetão. Percebemos ali que os "pontos" de prostituição das travestis são territórios permeados por disputas, atividades ilegais e relações assimétricas de poder. As nossas entrevistadas, nesse ínterim, nos esclareceram que os cafetões e cafetinas cobram para permitir o acesso ao ponto (que, em tese, deveria ser uma rua, pública).

“(...) não é livre não, tem esse negócio [de cobrarem pelo ponto]. Tal lugar, tal ponto é de fulana, tal ponto é de outra, e aí você tem que dar um dinheirinho ' $x$ ' para elas, para poder trabalhar naquele lugar" (Vera Cruz, 2017).

Descobrimos que as cafetinas e cafetões possuem papéis adicionais, além do agenciamento do "ponto": fornecem moradias, sobretudo às travestis vindas de outras cidades e Estados (os pensionatos em que Zahara, Vera Cruz e Lola alegaram morar perfazem acomodações organizadas pelos cafetões e cafetinas); fornecem insumos 
para a modificação e/ou "montagem" do corpo (hormônios, cabelos, roupas e demais "acessórios"); controlam horários, condutas e, consequentemente, estabelecem regras e eventuais punições (estas últimas relacionadas com intimidações, agressões físicas e, em casos extremos, a morte); além de serem as responsáveis - principalmente no caso das cafetinas identificadas como "bombadeiras" - de aplicarem silicone industrial em partes do corpo das travestis, de modo clandestino, precário e brutalizado.

A temática do silicone emergiu de modo recorrente, nas nossas interações com as travestis. Percebemos que todas as nossas entrevistadas possuíam silicone em partes do corpo, sobretudo na bunda e nos seios. $\mathrm{O}$ uso do silicone permeia o imaginário das travestis como algo que, apesar de ser aplicado de modo precário, clandestino e doloroso, ainda assim é um expediente necessário para que elas se sintam bem e bonitas. Foi curioso notar que, à ótica das nossas entrevistadas, o uso do silicone é visto como "a dor da beleza", conforme destaca Pelúcio (2005, p. 102) em suas investigações empíricas com as travestis.

"Ah, eu sei que é um risco né, mas eu cada vez mais, enquanto eu não estiver do jeito que eu quero, eu vou correr esse risco. Realmente pode morrer, porque não vai ter...se der uma parada cardíaca não vai ter uma equipe médica pra ajudar" (Lola, 2017).

"Já tive uma amiga minha que morreu com silicone. Porque é muito perigoso um silicone, não é certo pôr. Todas nós sabe que nós estamos correndo risco e...é perigoso morrer. Por que silicone é sorte. Todas falam isso, todas as travestis sabem disso, silicone é sorte. Se você passou, agradeça" (Zahara, 2017).

"Se a bombadeira quiser te matar, ela te mata. Só com uma agulhada ela mata a gente" (Paquita, 2017).

As falas das travestis entrevistadas permitiram-nos inferir que a aplicação do silicone é uma prática violenta: realizada de modo precário, clandestino, por pessoas não capacitadas, com o uso de materiais inadequados (foi recorrente a fala de que o que se usa, nas intervenções com as travestis, é o silicone industrial), em que é iminente o risco de morte. Além disso, ficou evidente que toda a dinâmica da aplicação do silicone ocorre sem que exista qualquer política pública e/ou estratégia de saúde que auxilie as travestis nos processos de mudança corpórea, por intermédio do silicone.

“(...) daí elas aplicam injeção em você e metem silicone pra você. Daí você é amarrada, até você...ficar boa pra ser desamarrada de novo" (Zahara, 2017).

“[O silicone] é sorte. Que nem todas dão certo, algumas rejeitam, algumas desce pro pé, alguns queimam, tudo. Eu tenho uma amiga minha em [outra cidade e Estado] que a pele da perna dela 
é tudo queimada do silicone. Ela não usa saia, short, nem nada" (Vera Cruz, 2017).

Ainda no que diz respeito aos processos de mudança corpórea das travestis, descobrimos que as cafetinas e cafetões também são os responsáveis por fornecer, em muitas circunstâncias, os hormônios que são usados para que, aos poucos, as travestis adquiram determinados traços femininos, conferindo a elas certa passabilidade, nos termos de Duque (2017). Os hormônios injetáveis, quando usados, são ministrados por outras travestis, "com a cara e a coragem", conforme nos disse Vera Cruz, que relatou ainda:

"[Os hormônios usados são] Perlutan e o Nordette, que é um comprimido. Perlutan é o que é aplicado, injetado, por amigas minhas. (...) Tomei hormônio um pouquinho de tempo, mas parei, começou a dar algumas reações no meu organismo e tive que parar..." (Vera Cruz, 2017).

Na medida em que fomos ampliando os nossos contatos e diálogos com as travestis, notamos que o modo como elas falam e se expressam é muito precário. Inferimos, com isso, que o nível de escolaridade delas é muito baixo - depois, elas próprias nos relataram isso. Das nossas entrevistadas, à exceção de Lola (que não quis nos dizer qual era seu nível de escolaridade), as demais sequer terminaram o ensino médio. Quando perguntamos o motivo pelo qual elas não tinham perseverado nos estudos, ficou evidente que o medo, os vários preconceitos e a falta de amparo (da família e da própria escola) representaram empecilhos para que elas continuassem estudando.

"Ah, é muita discriminação na escola, muito deboche, sabe. Os bofe, os maloqueiros lá ficam debochando da cara, sabe...fica rindo da cara da travesti e então eu já não quis mais ir para a escola por causa disso" (Agrado, 2017).

“(...) até na escola a gente somos rejeitada pela sociedade, que trata a gente mal, não chama a gente pelo nome feminino. E na escola mesmo os guri caçoava de mim, ria de mim por eu ser desse jeito. E eu resolvi parar, lá mesmo [na cidade em que nasceu] eu parei de estudar, por conta do preconceito que eu recebi" (Zahara, 2017).

"Pelos guris sim [sofreu preconceito], os guris ficavam revoltados [por ela andar só com menina, na escola]" (Paquita, 2017).

Ao explorarmos a temática do motivo pelo qual elas abandonaram a escola, o relato de Zahara chamou a nossa atenção. Ela referiu-se à negação do direito ao uso do nome social como um aspecto que a causava muita dor, sofrimento e medo, inclusive fazendo com que ela tenha abandonado o ambiente escolar precocemente. 
Quando questionada se não havia alguém na escola que tivesse zelado pelo respeito ao nome com o qual Zahara se identificava, ela afirmou:

"Não. E a diretora, a professora...eu falei pra ela me chamar [pelo nome social], ela disse 'não, você é um menino, e você tem que ser chamado assim. Seu nome não é esse', na época que eu tava estudando. (...) meu sonho é voltar a estudar e terminar meus estudos. Eu não volto porque eu tenho medo" (Zahara, 2017).

Em suma, Zahara nos lembrou da importância do nome social e da necessidade de se garantir o direito à alteração do registro civil das travestis, este último um aspecto garantido pelo Supremo Tribunal Federal (STF) em 2018. O nome social e o devido registro civil conforme a identidade de gênero da pessoa, muito embora não equacionem a bom termo as várias demandas das travestis, ainda assim são aspectos básicos para a garantia de cidadania e dignidades básicas a essas pessoas (Moreira et al, 2018).

Os baixos níveis de escolaridade das travestis, somados ao contexto de subalternidade e estigmatização dessas pessoas, fatalmente as empurram para o contexto da prostituição de rua. Notamos, na fala nas nossas entrevistadas, que muito embora elas desejassem ocupar outro tipo de função laboral, elas acabavam não conseguindo emprego. Além disso, a prostituição (“fazer rua”, como elas dizem) é algo que proporciona retornos financeiros fáceis.

“(...) porque você leva currículo o povo olha pra sua cara, não quer dar serviço, sabe? Isso aí chama discriminação. E aí eu prefiro rua, pra fazer programa, pra sustentar e ganhar dinheiro porque não dão serviço pra ninguém" (Agrado, 2017).

"Eu cheguei a essa profissão [prostituição de rua] por que é muito difícil alguém querer dar emprego pra uma trans. Sendo travesti é difícil você ver oportunidade" (Zahara, 2017).

De todo modo, a despeito dos retornos financeiros aparentemente fáceis, notamos que a prostituição de rua, pelas travestis, é uma atividade cercada de muita violência e opressão: além de elas terem que se submeter às regras do cafetão ou cafetina para "bater ponto" em determinados espaços territorializados pela prostituição, não são incomuns os casos de agressões físicas, uso de drogas, além da pressão para que a atividade sexual, tonada "mercadoria" no âmbito da prostituição, ocorra de determinadas formas (sem o uso de preservativos, por exemplo).

"Eu saí com um cliente. Ele me esfaqueou por que eu não quis ficar com ele no quarto, tinha pagado 50 reais e tava usando droga. Ele queria me obrigar que eu ficasse com ele no quarto e usasse droga com ele. Eu fui agredida, tomei várias facadas" (Zahara, 2017). 
Outro aspecto que saltou aos nossos olhos, nas interações com as nossas entrevistadas, foi o contexto de abandono por elas vivido. Mesmo Agrado e Paquita, que vivem com membros da família, possuem relatos de abandono, preconceito por parte da família, além de dificuldade, manifestada principalmente pelos pais e irmãos, de aceitarem a condição delas, de se reconhecerem enquanto travestis. Assim sendo, elas acabam saindo da casa dos pais muito cedo (aos 12 ou 13 anos), o que contribui também para que sejam direcionadas para a prostituição (que é uma atividade que normalmente "as recebe", proporcionando-lhes ganhos financeiros fáceis).

Pareceu-nos que a prostituição é algo compulsório na vida das travestis. O contexto de abandono familiar, baixa escolarização, ausência de empregos, preconceitos e estigmas - conforme já analisado nos parágrafos anteriores -, é ainda somado à perspectiva da "fetichização" dos corpos travestis, numa dinâmica em que este último aspecto faz com que as travestis sejam demandadas, no universo da prostituição, sobretudo pelo fato possuírem pênis (que, nesse ínterim, remete ativamente ao fetiche; à perspectiva da "mulher com pênis") (Pelúcio, 2007).

De todo modo, notamos que a fetichização dos corpos travestis é uma via de mão dupla: ao mesmo tempo que ampliam a atratividade das travestis no universo da prostituição de rua, impedem, por outro lado, que as elas empreendam esforços mais contundentes na transformação do corpo e no uso de mais hormônios femininos, por exemplo - as nossas entrevistadas relataram que o uso de hormônios femininos dificulta a ereção, o que as impede de atender adequadamente os clientes passivos na relação sexual, por exemplo.

Não obstante, percebemos que a temática da cirurgia de redesignação sexual não é algo que interessa muito as nossas pesquisadas. Pareceu-nos que o rechaço a esse tipo de possibilidade decorre da percepção, pelas travestis, de que uma eventual redesignação sexual retiraria a atratividade que elas possuem, no universo da prostituição de rua.

Portanto, fica evidente que as travestis, para além dos estigmas, exclusão, preconceito e abandono, também sofrem toda a sorte de pressões e violências, não raro de caráter emocional, até na hora de decidirem detalhes quanto ao modo como performatizarão, efetivamente, a sua identidade de gênero.

\section{E quanto ao destino da Geni, afinal, o que esperar?}

As Genis do nosso trabalho são seres constantemente subalternizados, atacados, violentados e mortos, seja de modo mais contundente, seja de modo mais sutil e velado.

Percebe-se que as agressões e violências contundentes têm escancarada a sua face mais cruel a partir do levantamento das informações que dão conta de que o Brasil é o país que mais mata travestis e transexuais, no mundo. 
Porém, as agressões e violências mais sutis (contudo, não menos cruéis e rechaçáveis) contra travestis manifestam-se: na ausência de uma estrutura que ampare as travestis no ambiente escolar, para que elas se sintam impelidas a não abandonarem a escola; na falta de uma consciência e de estratégias organizacionais que ampliem as oportunidade de emprego à esse público; na ausência de uma estrutura pública de saúde que ampare e oriente as travestis ao longo de seus processos de modificação corpórea, sobretudo no que tange ao uso adequado e "legal" do silicone; na escassez de uma política pública sistemática que forneça o tratamento para o HIV/AIDS, por parte desse público; sem contar a ausência de esforços que resultem em uma mudança de percepção, por parte da sociedade, para que as travestis sejam vistas como pessoas que merecem dignidade, respeito e acesso à direitos básicos.

É urgente que as travestis sejam tiradas das sombras e, portanto, da condição de absoluta subalternidade e exclusão. É crucial (re)conhecer esse público, inclusive por intermédio dos organismos oficiais de "produção de estatísticas", tais como o IBGE, que ainda não contempla estratégias específicas para o mapeamento da quantidade, perfil e principais demandas do público das pessoas travestis e transexuais, no Brasil.

Entendemos que pode haver um conjunto de ações, que passam principalmente pelo expediente das políticas públicas, que melhorariam a condição de vida das pessoas travestis e, por conseguinte, coibiriam o conjunto de múltiplas violências que leva sofrimento a esse público. Dentre as ações percebidas como urgentes e necessárias, destacam-se:

a) $\mathrm{O}$ efetivo combate às práticas de homofobia e, particularmente, de transfobia, recentemente criminalizadas pelo Supremo Tribunal Federal (STF) em um julgamento importante e histórico;

b) A criação de uma agenda específica, pública, de atendimento à saúde das travestis, que as ampare, inclusive, nos processos de mudança corpórea, em conformidade com sua identidade de gênero;

c) A incorporação do debate sobre identidade de gênero no ambiente escolar, estimulando a cultura da tolerância e respeito às travestis e transgêneros, nas escolas;

d) A consolidação de mecanismos que garantam o direito ao uso do nome social e a mudança do registro civil das pessoas travestis e transexuais. A despeito do nome social ser um direito das pessoas travestis e transexuais, percebe-se que há muitas barreiras, não raro sutis, que tentam impedir o acesso a esse tipo de direito;

e) $\mathrm{O}$ estabelecimento de estímulos (por intermédio de algum subsídio específico e/ou renúncia fiscal, por exemplo) para que as empresas disponibilizem vagas de emprego para travestis e transexuais;

f) A criação de uma agenda de debates e reflexões para que sejam pensadas políticas públicas e estratégias de ações afirmativas que contemplem o público de travestis e transexuais, não raro reservando vagas para essas pessoas em universidades ou concursos públicos, por exemplo. 
Enfim, julgamos que as ações acima sumarizadas são contribuições que emergiram do debate protagonizado neste artigo; são saídas que podem ser engendradas no âmbito dos diversos ativistas em direitos humanos e organizações da sociedade civil que lutam constantemente para a implementação de políticas públicas comprometidas com o reconhecimento das diferenças. $\mathrm{O}$ que o Brasil não pode, em hipótese alguma, é continuar nutrindo um ambiente em que Dandaras e Genis são "apedrejadas" e mortas todos os dias, numa dinâmica em que boa parcela da sociedade assiste, inerte, à verdadeira espetacularização do horror e da violência contra as travestis.

\section{Referências}

ARAÚJO, Murillo Clementino. (2018). O tempo, o valor e a prostituta: reflexões sobre "Geni e o Zepelim" de Chico Buarque. Estudos Semióticos, v.14, n.2, p.87-98. https:// doi.org/10.116o6/issn.1980-4016.esse.2018.150525

ANTRA - Associação Nacional de Travestis e Transexuais do Brasil. (2019). Dossiê: Assassinatos e violência contra travestis e transexuais no Brasil em 2018. Salvador: Antra Brasil.

BAGAGLI, Beatriz Pagliarini. (2016). A diferença trans no gênero para além da patologização. Periódicus - Revista de Estudos Interdisciplinares em Gêneros e Sexualidades, v.1, n.5, p.87-10o. http://dx.doi.org/10.9771/peri.vii5.17178

BENTO, Berenice. (2014). Brasil: país do transfeminicídio. Rio de Janeiro: Centro Latino-Americano em Sexualidade e Direitos Humanos (CLAM).

BENTO, Berenice. (2018). Necrobiopoder: Quem pode habitar o Estado-nação? Cadernos Pagu, n.53, p.1-16. http://dx.doi.org/10.1590/18094449201800530005

BORBA, Rodrigo. (2014). A linguagem importa? Sobre performance, performatividade e peregrinações conceituais. Cadernos Pagu, v.43: p.441-473. http://dx.doi. org/10.1590/0104-8333201400430441

BUTLER, Judith. (2004). Undoing gender. $1^{\text {st }}$. ed. New York: Routledge. https://doi. org/10.4324/9780203499627

BUTLER, Judith. (2016). Problemas de gênero: feminismo e subversão da identidade. 11… ed. Rio de Janeiro: Civilização Brasileira. 
CARVALHO, Mario. (2018). “Travesti", "mulher transexual”, "homem trans" e "não binário”: interseccionalidades de classe e geração na produção de identidades políticas. Cadernos Pagu, v.52, p.1-35. http://dx.doi.org/10.1590/18094449201800520011

COSTA, Cicera Glaudiane Holanda; ADRIÃO, Karla Galvão; CAVALCANTI, Céu Silva. (2015). As experiências de pessoas trans*: relatos sobre corpos, abjeções e direitos. Quaderns de Psicologia,v.20, n.3,p.99-11o. https://doi.org/10.5565/rev/qpsicologia.1271

D’AANGELO Luisa Bertrami et al. (2018). Performatividades de gênero em unidades prisionais femininas do Rio de Janeiro. Psicologia: Ciência e Profissão, v.38, n.spe.2, p.44-59. http://dx.doi.org/10.159o/1982-3703000212199

DIAS, Danilo.; SOUZA, Marcos Lopes de. (2019). "Parece uma mulher, mas é um traveco": produções discursivas marginais e transfóbicas nas vivências de uma travesti professora. Revista Espaço Acadêmico, v.18, n.212, p.19-30.

DUQUE, Tiago. (2012). Reflexões teóricas, políticas e metodológicas sobre um morrer, virar e nascer travesti na adolescência. Revista Estudos Feministas, v.20, n.2, p.489500. http://dx.doi.org/10.1590/So104-026X2012000200010

DUQUE, Tiago. (2017). Gêneros incríveis: um estudo sócio-antropológico sobre as experiências de (não) passar por homem e/ou mulher. Campo Grande: Ed. UFMS.

EFREM FILHO, Roberto. (2016). Corpos brutalizados: conflitos e materializações nas mortes de LGBT. Cadernos Pagu, v.46, p.311-340. http://dx.doi.org/10.159o/180944492 01600460311

FERREIRA, Guilherme Gomes. (2014). Violência, intersecionalidades e seletividade penal na experiência de travestis presas. Temporalis - Revista da Associação Brasileira de Ensino e Pesquisa em Serviço Social, v.14, n.27, p.99-117.

GIONGO, Carmem Regina; MENEGOTTO, Lisiane Machado de Oliveira; PETTERS, Simone. (2012). Travestis e transexuais profissionais do sexo: implicações da Psicologia. Psicologia: Ciência e Profissão, v.32, n.4, p.100o-1013. http://dx.doi.org/10.159o/S141498932012000400017

JESUS, Jaqueline Gomes de (2014). Gênero sem essencialismo: feminismo transgênero como crítica do sexo. Revista Universitas Humanística, v.78, p.241-258. http://dx.doi. org/10.11144/Javeriana.UH78.gsef

LIMA, Fátima. (2018). Raça, interseccionalidade e violência. Cadernos de Gênero e Diversidade, v.4, n.2, p.66-82. http://dx.doi.org/10.9771/cgd.v4i2.26646 
LOPES, Zaira de Andrade. (2009). Representações sociais acerca da violência de gênero: significados das experiências vividas por mulheres agredidas. Tese (Doutorado em Psicologia) - Faculdade de Filosofia, Ciências e Letras de Ribeirão Preto (FFCLRP), Universidade de São Paulo (USP), Ribeirão Preto, mimeo.

MELO, George Souza de. (2018). O caso Dandara dos Santos: sobre a violência e o corpo dissidente. Periódicus - Revista de Estudos Interdisciplinares em Gêneros e Sexualidades, v.1, n.10, p.78-84. http://dx.doi.org/10.9771/peri.v1i10.27751

MINAYO, Maria Cecília de Souza; SOUZA, Edinilsa Ramos de. (1997). Violência e saúde como um campo interdisciplinar e de ação coletiva. História, Ciência, Saúde Manguinhos, v.4, n.3, p.513-531. http://dx.doi.org/10.159o/So104-59701997000300006

MISKOLCI, Richard; PELÚCIO, Larissa. (2007). Fora do sujeito e fora do lugar: reflexões sobre performatividade a partir de uma etnografia entre travestis. Revista Gênero, v.7, n.2, p.257-269. https://doi.org/10.22409/rg.v7i2.155

MOREIRA, Maria Ignez Costa etal. (2018). Mulheres, travestis etransexuais: interseções de gênero em documentos de políticas públicas. Fractal: Revista de Psicologia, v. 30, n.2, p.234-242. https://doi.org/10.22409/1984-0292/v30i2/5545

NOLASCO, Gabriel Luis Pereira. (2018). Dar a cara a tapa: a (trans)formação de gênero das travestis. Dissertação (Mestrado em Psicologia) - Faculdade de Ciências Humanas (FACH), Universidade Federal de Mato Grosso do Sul (UFMS), Campo Grande, mimeo.

OLIVEIRA, Greciane Martins de; NOLASCO, Gabriel Luis Pereira. (2017). "Eu tô viva": Um diálogo sobre sexualidade, corpos e subjetividades a partir da (inter)ação com profissionais do sexo em Campo Grande/MS. In: SEMINÁRIO INTERNACIONAL FAZENDO GÊNERO, 11, Florianópolis.

PELÚCIO, Larissa; DUQUE, Tiago. (2013). “...Depois, querida, ganharemos o mundo”: reflexões sobre gênero, sexualidade e políticas públicas para travestis adolescentes, meninos femininos e outras variações. Revista de Ciências Sociais, v.44, n.1, p.10-43.

PELÚCIO, Larissa. (2005). “Toda quebrada na plástica” - corporalidade e construção de gênero entre travestis paulistanas. Revista Campos, v.6, n.1-2, p.97-112. http:// dx.doi.org/10.5380/cam.v6io.4509

PELÚCIO, Larissa. (2007). "Mulheres com Algo Mais" - corpos, gêneros e prazeres no mercado sexual travesti. Revista Versões, v.3, p.77-93. 
RODRIGUES, Carla; HEILBORN, Maria Luiza. (2014). Construyendo a Vera Cruz y deconstruyendo género: aproximaciones entre Pedro Almodóvar y Judith Butler. Sexualidad, Salud y Sociedad, v.16, p.73-85. http://dx.doi.org/10.159o/S198464872014000100005

TGEU - Transgender Europe. (2017). O círculo vicioso da violência: pessoas trans e gênero-diversas, migração e trabalho sexual. Berlim: Laserline Druckzentrum Berlin KG.

ZAGO, Luiz Felipe. (2014). Quando a norma range os dentes - corpo, norma e transgressão. Textura - Revista de Educação e Letras, v.16, n.31, p.140-155.

Recebido em 23/o8/2019.

Aceito em 29/03/2020. 